\title{
Effect of Two Standardized Oral Hygiene Methods on Bacterial Colonization in Mechanically Ventilated Patients
}

\author{
Marwa M. Abd Elbaky, Ibrahim Abbas Youssef , Azza Hamdi El-Soussi \& Mervat Anwar Abd El-Aziz. \\ Assist Lecturer of Critical Care Nursing, Faculty of Nursin, Minia University, Egypt. \\ Prof. of Anesthesia., Faculty of Medicine, Minia University, Egypt. \\ Prof. of Critical Care Nursing, Faculty of Nursin, Alexandria University, Egypt. \\ Lecturer of Critical Care Nursing, Faculty of Nursing, Assuit University, Egypt.
}

\begin{abstract}
Oral hygiene is an essential aspect of daily nursing care activity, Oral hygiene in critical often neglected or performed inadequately. Literature cited many oral hygiene solution as Chlorhexidine, Sodium Bicarbonatele, hydrogen peroxide and normal saline. Oral hygiene solutions leads to decrease colonization of the oropharynx, remove debris, and lowers VAP level. Literatures did not mention the most effective method including the solutions and the appropriate frequency of oral hygiene for critical ill patients. The aim of study: is to evaluate the effect of two standardized oral Hygiene methods on bacterial colonization in mechanically ventilated patients. Patients and method: A quasi experimental research was conducted at ICU of Minia university hospital. Sixty adult critical patients assigned randomly in two groups, 30 for each. Chlorhexidine $(0.2 \%)$ group (A) and Sodium Bicarbonate $(0.1 \%)$ group (B). Three tools used : Bacterial Colonization Indicators, Beck Oral Assessment Scale \& MucosalPlaque scale. Results: on 7th day of the study a higher percentage (87\%) of Chlorhexidine group (A) had good oral integrity, and only $(26.7 \%)$ of the same group had VAP than group (B) $(73.3 \%)$. Conclusions: Oral hygiene using tooth brushing with Chlorhexidine leads to improve oral cavity reducing colonization as well as VAP prevention.
\end{abstract}

Key Words: Oral Hygiene Methods - Chlorhexidine - Sodium Bicarbonate - Bacterial Colonization \& Mechanically Ventilated Patient

\section{Introduction}

Patients in the intensive care unit (ICU) have a very specific care needs, demanding the highest standard of professional care. Frequently, the life saving nature of the ICU means the patient's oral care takes low priority. Patients receiving mechanical ventilation (MV) have decreased salivary secretion, and oral cavity hygiene worsens, resulting in bacteria overgrowth. The aspiration of microorganisms present in the oropharynx constitutes the most common means of acquiring the disease. (Pedreira et al., 2009).

When oral care is not provided to a person who is mechanically ventilated the tooth surface may harbor many respiratory pathogens as Klebsiella pneumoniae, Staphylococcus aureus, Acinetobacter species, Escherichia coli, Enterobacter species, Serratia species, and Pseudomonas aeruginosa, the latter of which is naturally able to form resistance to many antibiotics and has a distinct odor that is sweet, slightly putrid, and frequently described as "fruity" or "grape-like." (Prendergast, et al., 2013).

The most commonly used antimicrobial agents is Chlorhexidine (CHX) , Chlorhexidine is a broad spectrum antibacterial oral rinse used to control plaque and prevent gingivitis., Chlorhexidine has a positively charged molecule, works by binding to negatively charged sites on tooth enamel and mucosal cells. This action results in a reduction of microbial adherence to the tooth and mucosal surfaces. If lower concentrations are used, it has a bactericidal effect, and has an inhibitory effect against Gram-positive and Gram-negative organisms (Munro et al., 2009).

Sodium bicarbonate (S.B) mouth rinse is a cleaning agent reported to reduce the viscosity of oral mucus, therefore enhancing the removal of oral debris. Sodium bicarbonate as a cleansing agent has the ability to dissolve mucus and loosen debris accumulated around the teeth. It also raises the oral $\mathrm{pH}$ and prevents overgrowth of bacteria and reduces colonization (Johnstone et al., 2010). If the commercially available solution is not used, care must be taken to ensure correct dilution when preparing the solution for use as a mouth-rinse. This is important because if the recommended concentration is not adhered to, the possibility of oral mucosa irritation may result (Hill et al., 2009).

For the intubated, unconscious patient the importance of good oral health reflects the dimension of preventive oral care in reducing colonization of 
potential respiratory pathogens as well as promoting holistic patient care (Malkin, 2009). Oral care intervention strategies are targeted to promote and maintain oral health with a dual role of preventing systemic disease as VAP (Prendergast, 2012).

\section{Significance of the study}

Methods of providing oral hygiene are controversial and no standard oral hygiene policies are available for determining frequency of oral hygiene in critically ill patients. Oral and dental care has been identified as preventive measures against acquiring VAP. (Goncalves, \& Brasil 2012). In Egypt; a study confirmed in Alexandria University Hospital demonstrated the overall rate of VAP was $11.3 \%$ and $44.4 \%$ of them died (Sallam et al., 2005). On reviewing nursing education programs, it was found that oral hygiene takes a low priority. Research is also needed to determine the impact of improved oral health on patients' outcome (Berry et al., 2007).

\section{The Aim of the Study}

The aim of this study is to evaluate the effect of two standardized oral Hygiene methods on bacterial colonization in mechanically ventilated patients.

\section{Specific objectives}

- Improving the integrity of the oral cavity for patients receiving oral hygiene methods as Chlorhexidine than those receiving oral hygiene with Sodium Bicarbonate.

- Decrease oral colonization in the group that received oral hygiene with Chlorhexidine than those receiving oral hygiene with Sodium Bicarbonate.

\section{Operational Definition}

Standardized: is the process of implementing specific guidelines, rules for common and repeated use, aimed at achieving optimum degree of order or uniformity in a given context, discipline, or field.

Oral Hygiene methods: is the practice of keeping the mouth clean and healthy by brushing to prevent building up of plaque, the sticky film of bacteria and food that forms on the teeth.

Oral Dysfunction: means abnormality in the oral cavity includes (libs, tongue, mucus membrane, and the teeth).

\section{Hypotheses}

The following research hypotheses were formulated:

- The oral integrity for patients receiving oral hygiene with Chlorhexidine $(0.2 \%)$ (Group A) will be less in plaque and inflammation than those receiving oral hygiene with Sodium Bicarbonate $(0.1 \%)$ (Group B).

- Oral dysfunction will be less in the groups whom will receive oral hygiene with Chlorhexidine $(0.2 \%)$ (Group A) than those receiving oral receiving oral hygiene with Sodium Bicarbonate $(0.1 \%)$ (Group B).

- Respiratory infection manifestations in the groups whom will receive oral hygiene with Chlorhexidine (0.2\%) (Group A) will be less than those receiving oral hygiene with Sodium Bicarbonate (0.1\%) (Group B).

- Respiratory colonization will be less in the group that received oral hygiene with Chlorhexidine $(0.2 \%)$ (Group A) than those receiving oral receiving oral hygiene with Sodium Bicarbonate $(0.1 \%)$ (Group B).

- Oral colonization will be less colonized with bacteria in the group that received oral hygiene with Chlorhexidine (0.2\%) (Group A) than those receiving oral hygiene with Sodium Bicarbonate (0.1\%) (Group B).

\section{Patients \& Method}

Research design: A quasi experimental research was conducted at ICU of Minia university hospital.

Sample if the study: Sixty adult patients admitted to the above mentioned ICU who required prolonged mechanical ventilation for more than 48 hours, only orally intubated (intubated within 24 hours of admission).

Group (A): received oral hygiene by dipping the toothbrush into $(20 \mathrm{ml})$ of Alcohol-Free Chlorhexidine $(0.2 \%)$ ( $\mathrm{q} 4$ hours).

Group (B): received oral hygiene by dipping the toothbrush into $(0.1 \%)$ of Sodium Bicarbonate $(20 \mathrm{ml}$ q 2 hours).

\section{- Exclusion criteria}

- A known respiratory tract infection as (pneumonia, bronchitis, and sinusitis), a systemic infection, oral surgery, oral inflammation, or ulcer

Tools:

First tool: Bacterial Colonization Indicators

$1^{\text {st }}$ part: Demographic data and clinical data assessment sheet which was developed by the researcher and used to provide information such as patients name, age, sex, clinical data of patients such as date of admission and medical diagnosis. In addition to level of conscious assessment by using the modified Glasgow coma score (GCS), adopted from (Chaari et al., 2013). Acute Physiology and Chronic Health Evaluation (APACHE score II) (El Azab et al., 2013) used to compare severity of illness between patients

$2^{\text {nd }}$ part: Laboratory Investigation Indicators: Data obtained can be used to interpret the cues and inferences for presence of oral and respiratory colonization that includes sputum culture sensitivity test from the ETT and oropharyngeal swab which reflects the presence of pathological bacterial 
colonization. The Clinical Pulmonary Infection Score (CPIS) for clinical diagnosis of VAP adopted from (Batiha, 2008). CPIS has a sensitivity of $93 \%$ and a specificity of $100 \%$ for diagnosis of VAP. It consists of five items: temperature, white blood cells count, character of tracheal secretions, infiltrates on chest radiograph, and $\mathrm{PaO} 2 /$ fraction of inspired oxygen each item takes a score from 0 to 2 for each item. If the total score is equal or more than (6) suspected pneumonia but if it is less than (6) it means no presence of pneumonia.

Second Tool: Beck Oral Assessment Scale (BOAS) It is used to assess the condition of the oral cavity to detect any dysfunction. BOAS was adopted from (Ames et al., 2011) which consists of five items that examines lips, gingival, tongue, teeth, and saliva every item is examined by inspection and takes a score from (1) to (4). The highest total score is (20) which mean severe dysfunction and the lowest is (5) which mean no dysfunction.

Third Tool: Mucosal-Plaque Scale (MPS)

The MPS was adopted from (Ames et al., 2011). MPS includes only (2) items that reflects an assessment of mucosal surfaces and plaque presence by inspection. If mucus membrane is normal it takes a score of (1) and if there is severe inflammation it takes a score of (4). Plaque is also assessed by inspection, if it is not visible it takes a score of (1) and if there is abundant amount of plaque, it takes a score of (4). MPS values range from (2) to (8); any score greater than (5) reflects remarkable lack of oral integrity.

\section{Methodology}

- This study was carried out after an official approval for data collection was obtained from ICU director and ethics committee in ICU of Minia University Hospital.

- The sample consists of sixty adult patients selected conveniently; they were enrolled in the study and assigned randomly into two groups (30) per each group.

- Ethical considerations: Informed consent was obtained by the researcher from patient's responsible person. Explanation about the study was done which included the aim of the study, potential benefits, risk and discomfort during participation.

- Confidentiality of data, privacy, voluntary participation and right to refuse to participate in the study were emphasized to patient's responsible person.

- Three tools were developed by the researcher after reviewing the relevant literature.

- Developed tools were tested for content validity, by a jury of (7) experts in the field of the study.

\section{Pilot study}

The Pilot study was conducted conveniently into (6) patients whom were excluded from the actual study because of the modifications that were done.

Data collection: Started from the $\left(1^{\text {st }}\right)$ of October (2012) until the $\left(30^{\text {th }}\right)$ of October (2013).

Study Procedure

-Preparatory phase

The following steps were conducted for both groups

- The researcher assessed critically ill mechanically ventilated patients in both groups (A \&B) and recorded their socio demographic and medical diagnosis before any data collection by taking this information from the medical sheet using tool one.

- The researcher assessed all critically ill mechanically ventilated patients from the first day of admission and consequently daily till the $\left(7^{\text {th }}\right)$ day of the study using tool one ( $1^{\text {st }}$ part) to detect early signs of respiratory infection.

- Initial assessment of patient's level of consciousness was done daily by using the modified GCS and the APACHE score II was used to determine the severity of illness, in addition to the CPIS score was used to detect the presence or absence of pneumonia.

Both the APACHE score II and the CPIS score were assessed at the $\left(1^{\text {st }}\right)$ day to provide base line data and follow up was done after that on the $\left(4^{\text {th }}\right)$ and $\left(7^{\text {th }}\right)$ day (tool one).

\section{Intervention phase}

- Hand washing and wearing gloves

- Patient was placed in lateral semi fowler position at (35-45 degree).

- Placement of mackintosh and towel over the patient's chest to the neck was done to prevent infection and soiling of patient's clothes.

- Hyper oxygenation was done before and after suctioning patient's oropharyngeal cavity to prevent de-saturation before oral care (by using manual resuscitation bag or by oxygen suction device of the machine).

- Oropharyngeal suction was done before and after procedure to remove excess oropharyngeal secretions or fluid to prevent aspiration.

- The BOAS and MPS were used to assess the condition of the oropharyngeal cavity before and after intervention ( $2^{\text {nd }}$ tool and $3^{\text {rd }}$ tool $)$.

- Assessment was done by placing a gloved finger or tongue depressor at the side of the mouth between teeth and cheek. Examination of the lips if dry, cracked, or caked. Palpitation of the lips with glove-covered index finger was done. The researcher used the penlight in a hand for better visualization of oral structures. The researcher 
examined the gingival surface for redness, swelling, injury, and bleeding by using a single layer of soft gauze wrap around the index finger. Examination of secretions for amount, viscosity, and color were made. Plaque also was assessed by inspection if it is not easily visible, small amounts, Moderate amounts and / or Abundant amounts of confluent plaque.

- ETT cuff pressure was checked (q 8 hours) and it ranged between ( 22 to $32 \mathrm{cmH} 2 \mathrm{O}$ ) to prevent aspiration of fluid during oral care procedure.

- ETT site was changed daily to prevent skin ulcer.

- ETT tape was changed daily and if wet.

- Kidney basin was placed over the towel and mackintosh under the chin to prevent wetting of patient's clothes.

- Padded tongue depressor or oral airway was gently placed from the angle of mouth toward the back molar area near the ETT to prevent patient from biting the ETT.

- Holding the tooth brush with antiseptic agents at (45 degree).

- Brushing in one continuous line starting at the left upper (LU) gingival surface of the teeth, to the right upper (RU).

- Right lower (RL) and to left lower (LL) gingival area.

- Clean tongue from the inner to outer aspect.

The following steps were conducted specific with each group.

- Group (A) received oral care by dipping the toothbrush into $(20 \mathrm{ml})$ of Alcohol-Free Chlorhexidine $(0.2 \%)$ ( $\mathrm{q} 4$ hours). The bottle of this solution contains $(300 \mathrm{ml})$; each $(100 \mathrm{ml})$ contains (0.2 \%) Chlorhexidine Gluconate, (0.04\%) Menthol, (0.06\%) Thymol, (0.09\%) Eucalyptol, and $(0.02 \%)$ Sodium Fluoride.

- Group (B) received oral care by dipping the toothbrush into $(0.1 \%)$ of Sodium Bicarbonate (20 $\mathrm{ml} \mathrm{q} 4$ hours).

The following steps were conducted for the two groups

- A tip of irrigating syringe was inserted into patient's mouth and rinse gently with a small amount of water.

- Using padded tongue depressor or suctioning to remove excess water and fluid to prevent aspiration.

- During brushing, the oropharyngeal cavity was moistening with water based lubricant to lips (Oral Balance Gel).

- Endotracheal tube was cleaned with the same tooth brush and antiseptic agent to remove plaque, mucus or debris if present at the outer surface of the tube.

- Patients were repositioned in comfortable position.
- Gloves were removed and hand hygiene was done. Evaluation phase

- Both groups (A and B) were evaluated using tool ( 2 and 3 ), in addition to part two of tool one which included laboratory investigation as swab from the oropharyngeal cavity and sputum culture sensitivity test.

- Opharyngeal swab was conducted early in the morning, researcher used a tongue depressor to gently press the tongue, and swab was introduced into the patient's mouth to the dorsal surface of the tongue. (The oropharynx) by using rotation motion in clock like direction, swab was taken without touching the patient's lateral walls of the buccal cavity to minimize contamination with the oral flora.

-The swabs were transported in sterile tubes to the laboratory (the microbiology laboratory) where they were inoculated on blood agar, chocolate and maconkey's agar. After (24 hours) of inoculation at (37c), they were examined for different colonies. Negative cultures were incubated for additional (24 hours) before discarding as negative.

- Sputum culture was taken from ETT, a sterile suction catheter was placed into the endotracheal tube without applying suction until resistance was met, and blindly wedged into a distal bronchus under complete sterile conditions. Gentle aspiration was performed without installing saline solution; the first aspirate was discarded, and the second aspirate was collected for evaluation. Aspiration of about $10 \mathrm{~mL}$ of tracheal secretion from the ETT by using sterile suction catheter was made. Then aspirates were directly collected into sterile container.

- The endotracheal aspirates (ETA) were delivered to the microbiological laboratory immediately as soon as it was collected. Plates were evaluated for growth at (24 and 48 hours) and discarded after (5 days). The number of bacteria in the original sample was expressed in colony-forming units (cfu) per milliliter. All micro-organisms were identified using standard laboratory methods. The threshold for positive culture defining pneumonia was $(104 \mathrm{cfu} / \mathrm{ml})$.

- Laboratory investigations were done at the ( $1^{\text {st }}$ day) and follow up was done at the (4th and $7^{\text {th }}$ day). Comparisons between the two different results were done within the group and between both groups. Samples used to detect the presence or absence of bacterial colonization of the oral cavity and VAP to determine the effect of both solutions in the reduction of bacterial colonization in all groups. 


\section{Statistical analysis}

- The collected data were analyzed using SPSS soft ware version 11 and tabulated Descriptive statistics as number, percentage, mean, standard deviation were used for comparing both groups and the independent $\mathrm{T}$ test were also used for verifying significance.

\section{Results}

Table (1): Comparison between both groups in relation to level of responsiveness (GCS), severity of illness (APACHE) and socio-demographics.

\begin{tabular}{|c|c|c|c|c|c|}
\hline \multirow{2}{*}{ Demographics Age } & \multirow{2}{*}{\multicolumn{2}{|c|}{$\begin{array}{c}\text { Mean } \pm \text { SD } \\
33.9 \pm 9.6\end{array}$}} & \multirow{2}{*}{\multicolumn{2}{|c|}{$\begin{array}{c}\text { Mean } \pm \text { SD } \\
37.9 \pm 10.5\end{array}$}} & \multirow{3}{*}{$\begin{array}{c}0.1 \\
\text { P value }\end{array}$} \\
\hline & & & & & \\
\hline Sex & No & $\%$ & No & $\%$ & \\
\hline Male & 24 & 80 & 16 & 53.3 & \multirow{2}{*}{$0.03 *$} \\
\hline Female & 6 & 20 & 14 & 46 & \\
\hline \multicolumn{6}{|l|}{ Education } \\
\hline Illiterate & 6 & 6.7 & 2 & 6.7 & \multirow[t]{3}{*}{0.3} \\
\hline Secondary & 10 & 73.3 & 9 & 33.3 & \\
\hline Bachelor & 14 & 20 & 19 & 60 & \\
\hline \multirow{2}{*}{$\begin{array}{c}\text { Severity of illness (APACH) } \\
\text { score II }\end{array}$} & \multicolumn{2}{|c|}{ Chlorhexidine (A) } & \multicolumn{2}{|c|}{ Sodium Bicarbonate $(\mathbf{B})$} & \multirow{2}{*}{ P value } \\
\hline & \multicolumn{2}{|c|}{ Mean \pm S.D } & \multicolumn{2}{|c|}{ Mean \pm S.D } & \\
\hline $1^{\text {st }}$ day & \multicolumn{2}{|c|}{$16.4 \pm 4.49$} & \multicolumn{2}{|c|}{$17.46 \pm 3.5$} & 0.5 N.S \\
\hline $4^{\text {th }}$ day & \multicolumn{2}{|c|}{$9.8 \pm 3.5$} & \multicolumn{2}{|c|}{$7.5 \pm 2.56$} & $<0.001 * * *$ \\
\hline $7^{\text {th }}$ day & \multicolumn{2}{|c|}{$6.6 \pm 5.2$} & \multicolumn{2}{|c|}{$8.13 \pm 4.20$} & $0.03 *$ \\
\hline \multicolumn{6}{|l|}{ Level of responsiveness (GCS) } \\
\hline GCS $1^{\text {st }}$ day & \multicolumn{2}{|c|}{$4.8 \pm 2.71$} & \multicolumn{2}{|c|}{$5.9 \pm 2.4$} & $0.16 \mathrm{NS}$ \\
\hline GCS $4^{\text {th }}$ day & \multicolumn{2}{|c|}{$7.23 \pm 3.6$} & \multicolumn{2}{|c|}{$5.9 \pm 2.4$} & $0.30 \mathrm{NS}$ \\
\hline $\mathrm{GCS}^{\text {th }}$ day & \multicolumn{2}{|c|}{$9.1 \pm 4.06$} & \multicolumn{2}{|c|}{$6.46 \pm 2.38$} & $0.01 * *$ \\
\hline
\end{tabular}

P>0.05: Not Significance (NS),

$P<0.01$ **: Moderate Significant,
$P<0.05^{*}:$ Significant,

$P<0.001 * * *:$ High Significance 
Table (2): Comparison between the two studied groups in relation to Mucosal Plaque Score (MPS).

\begin{tabular}{|c|c|c|c|c|c|c|}
\hline \multirow{2}{*}{ MPS $1^{\text {st }}$ day } & \multicolumn{2}{|c|}{ Chlorhexidine (A) } & \multicolumn{2}{|c|}{ Sodium Bicarbonate $(\mathrm{B})$} & \multirow[t]{2}{*}{$\mathbf{X} 2$} & \multirow[t]{2}{*}{ Total P Value } \\
\hline & No & $\%$ & No & $\%$ & & \\
\hline Good oral integrity & 4 & 13.3 & 6 & 20 & \multirow[t]{4}{*}{6.9} & \multirow{4}{*}{$\begin{array}{l}0.32 \\
\text { N.S }\end{array}$} \\
\hline Mild lack of oral integrity & 6 & 20 & 3 & 10 & & \\
\hline Moderate lack of oral integrity & 8 & 26.7 & 8 & 26.7 & & \\
\hline Marked lack of oral integrity & 12 & 40 & 13 & 43.3 & & \\
\hline Total mean (Mean \pm S.D) & \multicolumn{2}{|c|}{$6.36 \pm 1.65$} & \multicolumn{2}{|c|}{$6.60 \pm 1.58$} & \multicolumn{2}{|c|}{$\mathrm{P}$ value 0.7 N.S } \\
\hline MPS 4 $4^{\text {th }}$ day & No & $\%$ & No & $\%$ & $\mathrm{X} 2$ & Total P Value \\
\hline Good oral integrity & 21 & 70 & 3 & 10 & \multirow[t]{4}{*}{24.5} & \multirow[t]{4}{*}{$<0.001 * * *$} \\
\hline Mild lack of oral integrity & 4 & 13.3 & 5 & 16.7 & & \\
\hline Moderate lack of oral integrity & 2 & 6.7 & 12 & 40 & & \\
\hline Marked lack of oral integrity & 3 & 10 & 10 & 33.3 & & \\
\hline Total mean $($ Mean \pm S.D) & \multicolumn{2}{|c|}{$2.73 \pm 1.41$} & \multicolumn{2}{|c|}{$5.96 \pm 1.67$} & \multicolumn{2}{|c|}{$\mathbf{P}$ value $<0.001 * * *$} \\
\hline \multirow{2}{*}{ MPS $7^{\text {th }}$ day } & \multicolumn{2}{|c|}{ Chlorhexidine (A) } & \multicolumn{2}{|c|}{ Sodium Bicarbonate (B) } & \multirow{2}{*}{$\mathbf{X} 2$} & \multirow{2}{*}{ Total $P$ value } \\
\hline & No & $\%$ & No & $\%$ & & \\
\hline Good oral integrity & 26 & 87 & 8 & 26.7 & \multirow[t]{4}{*}{23.4} & \multirow[t]{4}{*}{$<0.001 * * *$} \\
\hline Mild lack of oral integrity & 2 & 6.7 & 5 & 16.7 & & \\
\hline Moderate lack of oral integrity & 1 & 3.3 & 8 & 26.7 & & \\
\hline Marked lack of oral integrity & 1 & 3.3 & 9 & 30 & & \\
\hline Total mean (Mean \pm S.D) & \multicolumn{2}{|c|}{$2.40 \pm 0.93$} & \multicolumn{2}{|c|}{$4.80 \pm 1.84$} & \multicolumn{2}{|c|}{$\mathbf{P}$ value $<0.001 * * *$} \\
\hline
\end{tabular}

P>0.05: Not Significance (NS),

$P<0.001$ ***: High Significance

$P<0.05^{*}:$ Significant,

$P<0.01^{* *}$, Moderate Significant,

$X 2=$ Chi square test.

Table (3): Comparison between the two studied groups in relation to Beck Oral Assessment Score (BOAS)

\begin{tabular}{|c|c|c|c|c|c|c|}
\hline \multirow{2}{*}{ BOAS $1^{\text {st }}$ day } & \multicolumn{2}{|c|}{ Chlorhexidine (A) } & \multicolumn{2}{|c|}{ Sodium Bicarbonate (B) } & \multirow[t]{2}{*}{$\mathrm{X} 2$} & \multirow{2}{*}{$\begin{array}{c}\text { Total P } \\
\text { Value }\end{array}$} \\
\hline & No & $\%$ & No & $\%$ & & \\
\hline No dysfunction & 3 & $\overline{10}$ & 5 & 16.7 & \multirow{4}{*}{3.1} & \multirow{4}{*}{0.8 N.S } \\
\hline Mild dysfunction & 3 & 10 & 5 & 16.7 & & \\
\hline Moderate dysfunction & 9 & 30 & 9 & 30 & & \\
\hline Severe dysfunction & 15 & 50 & 11 & 36.7 & & \\
\hline Total mean (Mean \pm S.D) & \multicolumn{2}{|c|}{$11.06 \pm 5.48$} & \multicolumn{2}{|c|}{$10.86 \pm 4.64$} & \multicolumn{2}{|c|}{$\mathrm{P}$ value 0.6 N.S } \\
\hline BOAS 4 $4^{\text {th }}$ day & No & $\%$ & No & $\%$ & $\mathbf{X 2}$ & Total P Value \\
\hline No dysfunction & 22 & 73.3 & 9 & 30 & \multirow[t]{4}{*}{15.9} & \multirow[t]{4}{*}{$0.001 * *$} \\
\hline Mild dysfunction & 6 & 20 & 6 & 20 & & \\
\hline Moderate dysfunction & 2 & 6.7 & 9 & 30 & & \\
\hline Severe dysfunction & - & - & 6 & 20 & & \\
\hline Total mean (Mean \pm S.D) & \multicolumn{2}{|c|}{$5.80 \pm 1.95$} & \multicolumn{2}{|c|}{$10.1 \pm 3.39$} & \multicolumn{2}{|c|}{$\mathrm{P}$ value $<0.001 * * *$} \\
\hline \multirow{2}{*}{ BOAS $7^{\text {th }}$ day } & \multicolumn{2}{|c|}{ Chlorhexidine (A) } & \multicolumn{2}{|c|}{ Sodium Bicarbonate (B) } & \multirow[t]{2}{*}{$\mathrm{X} 2$} & \multirow{2}{*}{$\begin{array}{c}\text { Total } \\
\text { P Value }\end{array}$} \\
\hline & No & $\%$ & No & $\%$ & & \\
\hline No dysfunction & 27 & 90 & 13 & 43.3 & \multirow[t]{4}{*}{15.1} & \multirow[t]{4}{*}{$\mathbf{0 . 0 0 2} * *$} \\
\hline Mild dysfunction & 1 & 3.3 & 3 & 10 & & \\
\hline Moderate dysfunction & 2 & 6.7 & 11 & 36.7 & & \\
\hline Severe dysfunction & - & - & 3 & 10 & & \\
\hline Total mean (Mean \pm S.D) & \multicolumn{2}{|c|}{$5.43 \pm 1.52$} & \multicolumn{2}{|c|}{$7.36 \pm 2.63$} & \multicolumn{2}{|c|}{$P$ value 0.001} \\
\hline
\end{tabular}


Table (4) Comparison between both groups in relation to the Clinical Pulmonary Infection Score (CPIS).

\begin{tabular}{|c|c|c|c|c|c|c|}
\hline \multirow{2}{*}{ CPIS $1^{\text {st }}$ day } & \multicolumn{2}{|c|}{ Chlorhexidine (A) } & \multicolumn{2}{|c|}{ Sodium Bicarbonate (B) } & \multirow{2}{*}{$\mathbf{X} 2$} & \multirow{2}{*}{$\begin{array}{c}\text { Total P } \\
\text { value }\end{array}$} \\
\hline & No & $\%$ & No & $\%$ & & \\
\hline No VAP & 30 & 100 & 30 & 100 & \multirow[t]{2}{*}{$\mathrm{NA}$} & \multirow[t]{2}{*}{ NA } \\
\hline VAP & - & - & - & - & & \\
\hline Total mean (Mean \pm S.D) & \multicolumn{2}{|c|}{$1.86 \pm 1.47$} & \multicolumn{2}{|c|}{$1.83 \pm 1.2$} & \multicolumn{2}{|c|}{$\mathrm{P}$ value $0.6 \mathrm{~N} . \mathrm{S}$} \\
\hline CPIS $4^{\text {th }}$ day & No & $\%$ & No & $\%$ & $\mathrm{X} 2$ & Total P value \\
\hline No VAP & 23 & 76.7 & 11 & 36.7 & \multirow{2}{*}{9.9} & \multirow{2}{*}{$0.002 * *$} \\
\hline VAP & 7 & 23.3 & 19 & 63.3 & & \\
\hline Total mean $($ Mean \pm S.D $)$ & \multicolumn{2}{|c|}{$2.96 \pm 2.3$} & \multicolumn{2}{|c|}{$5.16 \pm 2.9$} & \multicolumn{2}{|r|}{$0.004 * *$} \\
\hline CPIS $7^{\text {th }}$ day & No & $\%$ & No & $\%$ & $\mathbf{X 2}$ & Total P value \\
\hline No VAP & 22 & 73.3 & 8 & 26.7 & \multirow{2}{*}{9.7} & \multirow{2}{*}{$<0.008 * * *$} \\
\hline VAP & 8 & 26.7 & 22 & 73.3 & & \\
\hline Total mean $($ Mean \pm S.D) & \multicolumn{2}{|c|}{$3.4 \pm 2.6$} & \multicolumn{2}{|c|}{$6.36 \pm 3.04$} & \multicolumn{2}{|c|}{$<0.001 * * *$} \\
\hline
\end{tabular}

P>0.05: Not Significance (NS)

$P<0.01^{* *}$, Moderate Significant

$P<0.05 *:$ Significant,

$P<0.001 * * *:$ High Significance, $X 2=$ Chi square test.

Table (5): Percent distribution comparing studied groups in relation to Culture Sensitivity test.

\begin{tabular}{|c|c|c|c|c|c|c|}
\hline \multirow[t]{2}{*}{ Culture Sensitivity test } & \multicolumn{2}{|c|}{$\begin{array}{c}\text { Chlorhexidine } \\
\text { (A) }\end{array}$} & \multicolumn{2}{|c|}{$\begin{array}{c}\text { Sodium Bicarbonate } \\
\text { (B) }\end{array}$} & \multirow[t]{2}{*}{$\mathbf{X} 2$} & \multirow[t]{2}{*}{ P. Value } \\
\hline & No & $\%$ & No & $\%$ & & \\
\hline \multicolumn{7}{|l|}{$1^{\text {st }}$ Time culture day 1} \\
\hline Negative (no presence of colonization) & 20 & 66.7 & 22 & 56.7 & \multirow[t]{2}{*}{0.31} & \multirow[t]{2}{*}{0.6 N.S } \\
\hline Positive (Presence of colonization) & 10 & 36.7 & 8 & 43.3 & & \\
\hline \multicolumn{7}{|l|}{$2^{\text {nd }}$ Time culture day 4} \\
\hline Negative (no presence of colonization) & 20 & 63.3 & 15 & 50 & \multirow[t]{2}{*}{1.73} & \multirow[t]{2}{*}{0.2 N.S } \\
\hline Positive (Presence of colonization) & 10 & 36.7 & 15 & 50 & & \\
\hline \multicolumn{7}{|l|}{$3^{\text {rd }}$ Time culture day 7} \\
\hline Negative (no presence of colonization) & 21 & 70 & 7 & 23.3 & \multirow[t]{2}{*}{13.1} & \multirow[t]{2}{*}{$<0.001 * * *:$} \\
\hline Positive (Presence of colonization) & 9 & 30 & 23 & 76.7 & & \\
\hline
\end{tabular}

P>0.05L: Not Significance (NS), $\quad P<0.05^{*}$ : Significant, $\quad P<0.01^{* *}:$ Moderate Significant, $\quad P<0.001^{* * *}$ :

High Significance, $(X 2)=$ Chi square test. 
Table (6) Comparison between the Studied groups in relation to throat swab results.

\begin{tabular}{|c|c|c|c|c|c|c|c|c|c|c|c|c|c|c|}
\hline & \multicolumn{6}{|c|}{ CHLORHEXIDENE (A) } & \multicolumn{6}{|c|}{ SODIUM BICARBONATE (B) } & \multirow[b]{2}{*}{$\mathbf{X} 2$} & \multirow[b]{2}{*}{$\begin{array}{c}\mathbf{P} \\
\text { value }\end{array}$} \\
\hline & 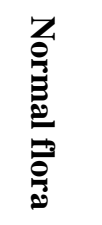 & 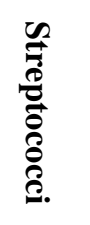 & 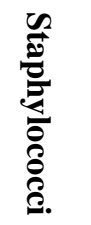 & 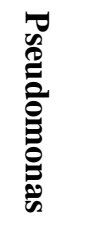 & 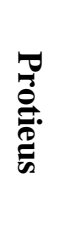 & 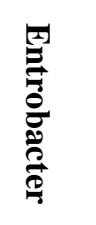 & $\begin{array}{l}Z \\
\text { Z } \\
0 \\
0 \\
0 \\
0 \\
0 \\
0 \\
0 \\
0\end{array}$ & 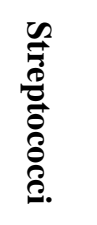 & 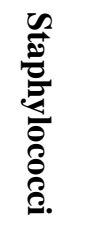 & 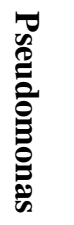 & 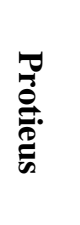 & 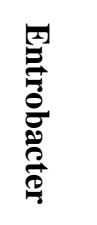 & & \\
\hline $\begin{array}{c}1^{\text {st }} \\
\text { day }\end{array}$ & $\begin{array}{c}20 \\
(66.7)\end{array}$ & $\begin{array}{c}1 \\
(3.3)\end{array}$ & $\begin{array}{c}3 \\
(10)\end{array}$ & $\begin{array}{c}4 \\
(13.3)\end{array}$ & $\begin{array}{c}1 \\
(3.3)\end{array}$ & $\begin{array}{c}1 \\
(3.3)\end{array}$ & $\begin{array}{c}19 \\
(63.3\end{array}$ & $\begin{array}{c}6 \\
(20)\end{array}$ & $\begin{array}{c}1 \\
(3.3)\end{array}$ & $\begin{array}{c}3 \\
(10)\end{array}$ & - & $\begin{array}{c}1 \\
(3.3)\end{array}$ & 8.6 & $\begin{array}{c}0.1 \\
\text { N.S. }\end{array}$ \\
\hline $\begin{array}{l}4^{\text {th }} \\
\text { day }\end{array}$ & $\begin{array}{c}19 \\
(63.3)\end{array}$ & $\begin{array}{c}2 \\
(6.7)\end{array}$ & $\begin{array}{c}2 \\
(6.7)\end{array}$ & - & - & $\begin{array}{c}7 \\
(23.3)\end{array}$ & $\begin{array}{c}15 \\
(50)\end{array}$ & $\begin{array}{c}2 \\
(6.7)\end{array}$ & $\begin{array}{c}4 \\
(13.3)\end{array}$ & - & $\begin{array}{c}1 \\
(3.3) \\
\end{array}$ & $\begin{array}{c}8 \\
(26.7)\end{array}$ & 2.2 & $\begin{array}{r}0.7 \\
\text { N.S. }\end{array}$ \\
\hline $\begin{array}{l}7^{\text {th }} \\
\text { day }\end{array}$ & $\begin{array}{c}18 \\
(60)\end{array}$ & $\begin{array}{c}5 \\
(16.7)\end{array}$ & $\begin{array}{c}7 \\
(23.3)\end{array}$ & - & - & - & $\begin{array}{c}10 \\
(33.3)\end{array}$ & $\begin{array}{c}5 \\
(16.7)\end{array}$ & $\begin{array}{c}5 \\
(16.7\end{array}$ & - & $\begin{array}{c}6 \\
(20)\end{array}$ & $\begin{array}{c}4 \\
(13.3)\end{array}$ & 12.6 & $0.01 *$ \\
\hline
\end{tabular}

$P>0.05$ : Not Significance (NS), $\quad P<0.05^{*}$ : Significant,

$P<0.01^{* *}$ : Moderate Significant, $\quad P<0.001^{* * *}$ High Significance, $(X 2)=$ Chi square test.

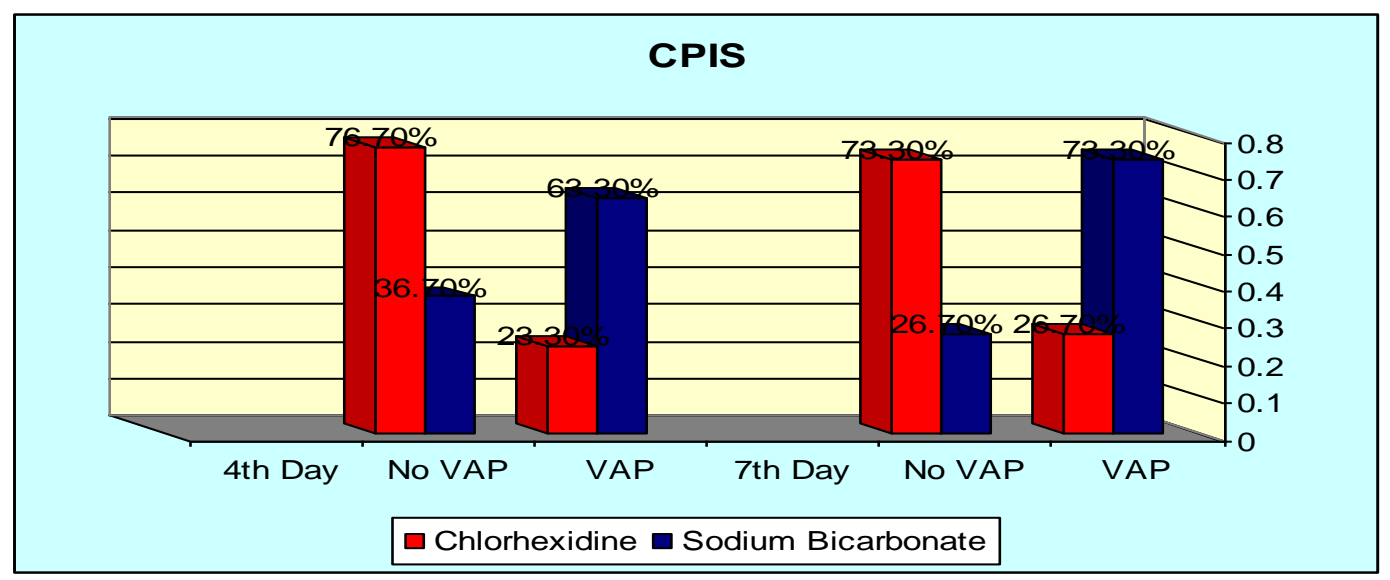

Figure (1) Shows that Chlorhexidine group had low level of VAP presence at the $4^{\text {th }}$ and $7^{\text {th }}$ day of the study

Table (1): Shows the severity of illness the APACHE score II in the $7^{\text {th }}$ day, it was observed that group (A) had a lower APACHE score II than group (B) $(6.6 \pm$ 5.2). Regarding to the age it was observed no statistically significant difference between both groups.

Table (2): Shows the condition of mucus membrane and level of plaque using the MPS, at the $4^{\text {th }}$ day, the majority of group (A) $(70 \%)$ had good oral integrity than group (B) $(10 \%)$ respectively and there were statistically significant difference among both groups presented by $\mathrm{P}$ value $(<0.001)$. at the $7^{\text {th }}$ day of the study it was observed that a higher percentage of group (A) $(86 \%)$ had good oral integrity than group (B) $(26.7 \%)$ there were statistically significant difference among them presented by $\mathrm{P}$ value $(<0.001)$.

Table (3): Assesses the condition of the oral cavity by using BOAS at the $4^{\text {th }}$ day the majority of group A $(73.3 \%)$ had no oral dysfunction than group (B) and there were statistically significant difference among them presented by $\mathrm{P}$ value (0.001). As regard to the $7^{\text {th }}$ day it was observed that a higher percent of group (A) $(90 \%)$ had no oral dysfunction than group (B) and there were statistically significance difference among them presented by $\mathrm{P}$ value $(<0.001)$.

Table (4): Shows comparison between both groups in relation to CPIS, it was observed that VAP presence at the $4^{\text {th }}$ day was less in the Chlorhexidine group (A) $(23.3 \%)$ than sodium bicarbonate group (B). With respect to the $7^{\text {th }}$ day it was observed that a lower percent of group (A) $(26.7 \%)$ developed VAP than group (B) and there were statistically significant difference among both groups presented by $\mathrm{P}$ value $(0.002 \& 0.001)$ respectively.

Table (5): Comparing both groups of the study in relation to bacterial colonization using culture sensitivity test, it was observed at the $7^{\text {th }}$ day the majority of group (A) (70\%) had no colonization 
result but only (23.3\%) of group (B) had the same result of culture test. There were statistically significant differences among both groups presented by $\mathrm{P}$ value $(0.001)$.

Table (6): Shows distribution percentage of the throat swab results in the two groups of the study it was observed at the $7^{\text {th }}$ day that the more than half of group (A) $(60 \%)$ had normal flora but only $(33.3 \%)$ of group (B) had the same result and there were statistically significant differences among both groups in the $7^{\text {th }}$ day presented by $\mathrm{P}$ value $(0.03)$.

\section{Discussion}

Oral hygiene has an impact on patient's comfort and enhances patient's sense of wellbeing. (Booker et al., 2013). Oral hygiene is an essential aspect of the daily nursing care provided by health professionals and is considered an effective strategy in reducing VAP in patients requiring MV (Prendergast et al., 2013). Oral hygiene in critical often has a low priority or assigned to the less trained person. The present study analyzed the effect of two standardized oral hygiene methods on bacterial colonization in mechanically ventilated patients.

This study was conducted at the ICU in Minia university .The used oral hygiene solutions in the study were (A) Chlorhexidine (0.2\%) and (B) Sodium Bicarbonate $(0.1 \%)$, both solutions were applied with the use of tooth brush and systemic technique during brushing. The study investigated its effect on the results of BOAS, MPS \& CPIS and also on bacterial colonization by using culture sensitivity test and throat swab result.

The current study showed the socio-demographic characteristics of the studied groups their mean and S.D of age was $33.9 \pm 9.6$ and $37.9 \pm 10.5$ respectively and the majority of them were male, with no statistical significant difference The finding is supported by Berry, (2013) which showed a higher presence of male sex group in their study with no significant difference in patient socio-demographic characteristics. Also Grap et al., (2011) found that (70 \%) of the studied group were males and their mean \pm SD of age $(42.36 \pm 18.22)$.

Regarding to the severity of illness which was assessed by the APACHE score II the present study showed there were statistical significance difference among them at the ( $4^{\text {th }}$ day) only. These results were similar to Ames et al., (2011), But El Azab et al., (2013) \& Berry et al., (2011) documented no significance change in mean score and standard deviations of the APACHE score II in the groups of the study.

To evaluate the effect of oral hygiene approaches on patient's oral cavity the present study started to evaluate the studied groups from the $4^{\text {th }}$ till the $7^{\text {th }}$ day of the study. It was observed that group (A) whom received oral hygiene using Chlorhexidine had improved their oral mucus membrane condition, and the level of plaque reduced than group (B) whom received oral care using sodium bicarbonate by using the MPS score. Also there were statistical significant differences observed among them from the $\left(4^{\text {th }}\right.$ day) till the ( $7^{\text {th }}$ day) of the study. It was observed also that Chlorhexidine improves the odor of the mouth and patient comfort.

Ames et al., (2011) supported the present study which found that MPS score was significantly lower in patients that received oral hygiene using brushing technique and Chlorhexidine, and they reported improved oral condition. But those received standard unit-based oral hygiene had higher MPS scores which reflecting poor oral health.

With respect to the oral cavity related structure which assessed using BOAS, the present study observed that (group A) had a higher percentage of no oral dysfunction using BOAS than group (B) from the $4^{\text {th }}$ till the $7^{\text {th }}$ day of the study, and there were statistical significant differences among both groups at the $\left(4^{\text {th }}\right.$ and $7^{\text {th }}$ day). The present study supported with Ames et al., (2011) whom found that BOAS was lower in the group that received oral hygiene using brushing technique with Chlorhexidine solutions than the other that received standard unit-based oral hygiene; they had higher BOAS which reflecting deteriorating oral health.

O Oshodi \& Bench, (2013) reported that the oral hygiene interventions, using tooth brushing and Chlorhexidine is the optimum method to ensure integrity of the oral cavity and decreasing colonization. In a study done by Batiha, (2008) found that the intervention group had improved oral condition in a higher percentage than the control group at the $\left(4^{\text {th }}\right.$ and $7^{\text {th }}$ day) of the study. There were statistical significant differences present between both groups.

With respect to VAP development the present study observed that (group A) had lower percentage of VAP and respiratory manifestations than group (B), which was assessed using CPIS scale at the $\left(4^{\text {th }}\right.$ and $7^{\text {th }}$ day). Hoshijima et al., (2013) \& Arroliga et al., (2014) agree with the present study and reported that oral hygiene using Chlorhexidine is effective in preventing VAP and the analysis showed that oral Chlorhexidine decontamination significantly reduced the incidence of VAP but not the mortality rate.

Regarding to bacterial colonization after using the oral hygiene methods was observed using culture sensitivity test. The majority of Group (A) whom received oral hygiene with Chlorhexidine had a higher percentage of no bacterial colonization (no 
growth) than group (B) whom received oral hygiene using sodium bicarbonate, with significant difference at the $7^{\text {th }}$ day of the study $(\mathrm{P}=<0.001)$ which reflect the antibacterial effect of Chlorhexidine on decreasing respiratory colonization for mechanically ventilated patient than that of the sodium bicarbonate. Choi \&Kim, (2012) were in line with the present study, they found that oral aerobic bacterial colonization in the Sodium Bicarbonate (S.B.) group was significantly higher than that of the Chlorhexidine group at the $\left(1^{\text {st }}, 7^{\text {th }}, 14^{\text {th }}, 21^{\text {st }}\right.$, and $28^{\text {th }}$ day) with significance $(\mathrm{p}=.001)$ for each day measured. Also (Johnstone, et al., 2010) stated that Sodium Bicarbonate is recommended for cleansing the oral cavity and breaking down tenacious saliva, but did not effective in decreasing bacterial colonization. Furthermore (Hill, et al., 2009) mentioned that Sodium Bicarbonate does not have any direct antimicrobial effects but has been used as a cleansing agent because of its ability to dissolve mucus and loosen debris.

Regarding to the type of bacteria that isolated from throat swab results it was observed that bacterial colonization was present in both groups in different percentage. But group (A) had a lower level of pathogenic bacteria as (Streptococci, Staphylococci $\&$ Entrobacter) than the other group. This describes the effect of tooth brushing with Chlorhexidine in reducing level of oral bacterial colonization of the respiratory system.

Baradari et al., (2012) reported that herbal mouth wash and Chlorhexidine have significant antibacterial effects against Streptococcus pneumoniae and Staphylococcus aureus. But Chlorhexidine was significantly more effective than herbal mouth wash in reducing the number of colonies $(p<0.001)$ (Berry, 2013) reported that Sodium Bicarbonate oral rinse was effective as a mouth wash but not more effective in the reduction of colonized dental plaque. It was also observed that Chlorhexidine is easy applicable mouth wash and less expensive for the patients, but sodium bicarbonate it was difficult to fine the required concentration for use. Nurses also preferred the use of Chlorhexidine than sodium bicarbonate because of its immediate effect on the patients mucus membrane.

Finally this study focuses on the importance of applying standardized oral hygiene strategy with evidence biased technique using soft pediatric tooth brush in combination with antiseptic solutions. Also oral hygiene intervention should be provided on regular frequencies every ( 2 to 4 hours) for critically ill patients. The mechanical action of a toothbrush to remove dental plaque has been recommended and is considered as a standard in applying oral hygiene and removing oral debris which interne reduces bacterial colonization and plaque.

\section{Conclusion}

It was concluded from the present study that oral hygiene strategy which includes the use of systemic technique in tooth brushing and the application of Chlorhexidine mouth wash ( $\mathrm{q} 4$ hours) led to improve the general condition of patient's oral cavity and reduced plaque level of development. This improvement appeared in lowering MPS and BOAS scores, VAP presence was also decreased after implementing oral hygiene strategy using Chlorhexidine.

\section{Recommendations}

- Hospitals and critical units should have written policy about standardized oral hygiene strategy.

- Nurses should be trained on how to perform oral assessment and oral hygiene for critical ill patients on regular frequencies.

- Oral hygiene for critical ill patients with ETT should be provided by using brushing with Chlorhexidine according to hospital facility every (2-4hours) and as indicated.

- Conducting new research about the same topic in order to cover large sample and providing updating to the standardized oral hygiene and the best solution that should be used.

\section{References}

1. Ames, N., Sulima, P., Yates, J., McCullagh, L., Gollins, S., Soeken, K., \& Wallen, G., (2011): Effects of systematic oral care in critically ill patients: a multicenter study. Am J Crit Care, 20(5), pp.103-114.

2. Arroliga, A., Pollard, C., \& Wilde, C., (2014): Reduction in the incidence of ventilatorassociated pneumonia: a multidisciplinary approach, Resp. Care journal, 57, pp. 688-696.

3. Baradari, A., Khezri, H., \& Arabi, S., (2012): Comparison of antibacterial effects of oral rinses Chlorhexidine and herbal mouth wash in patients admitted to intensive care unit., Pediatr Nurs, 113(9), pp. 556-560.

4. Batiha, A., (2008): Effect of implementing oral care protocol on the occurrence of ventilator associated pneumonia, doctoral thesis, faculty of nursing, Alexandria University.

5. Berry, A., Davidson, P., Masters, J., \& Rolls, K., (2007): Systematic literature review of oral hygiene practices for intensive care patients receiving mechanical ventilation. Am J Crit Care, 16(6), pp. 552-562. 
6. Berry, S., Zhu, Y., Choi, H., Kiel, D., \& Zhang, Y., (2013): Diuretic initiation and the acute risk of hip fracture. Osteoporos Int, 24(2), pp. 689-695.

7. Booker, S., Murff, S., Kitko, L., \& Jablonski, R., (2013): Mouth care to reduce ventilatorassociated pneumonia. Am J Nurs, 113(10), pp. 24-31.

8. Chaari, A., Kssibi, H., Zribi, W., Medhioub, F., Chelly, H., Algia, N., Bouaziz, M., (2013): Ventilator-associated pneumonia in trauma patients with open tracheotomy: Predictive factors and prognosis impact. J Emerg Trauma Shock, 6(4),pp. 246-251.

9. Choi, S., \& Kim, H., (2012): Sodium Bicarbonate Solution versus Chlorhexidine Mouthwash in Oral Care of Acute Leukemia Patients Undergoing Induction Chemotherapy: A Randomized Controlled Trial. Asian Nurs Res (Korean Soc Nurs Sci), 6(2), pp. 60-66.

10. El Azab, R., El Sayed, E., Abdelkarim, M., Al Mutairi, B., Al Saqabi, A., \& El Demerdash, S., (2013): Combination of ventilator care bundle \& regular oral care with Chlorhexidine was associated with reduction in ventilator associated pneumonia, Egyptian Journal of Anesthesia, Vol 29, pp273-277.

11. Goncalves, F., \& Brasil, V., (2012). Nursing actions for the prevention of ventilatorassociated pneumonia. Acta Paul Enferm.; 25 (Special Issue 1):10.

12. Grap, M., Munro, C., Hamilton, V., Elswick, R., J., Sessler, C., \& Ward, K., (2011): Early, single Chlorhexidine application reduces ventilator-associated pneumonia in trauma patients. Heart Lung, 40(5), pp.115-122.

13. Hill, J., Mccreary, T., \& Kolb, D., (2009): Chemistry for changing times, 12th edition, New Jersey: Prentice Hall.

14. Hoshijima, H., Kuratani, N., Takeuchi, R., \& Shiga, T., (2013): Effects of oral hygiene using Chlorhexidine on preventing ventilatorassociated pneumonia in critical-care settings: A meta-analysis of randomized controlled trials, Journal of Dental Sciences, 8, pp. 348-357.

15. Johnstone, L., Spence, D., \& Koziol-McClain, J., (2010): Oral hygiene care in the pediatric intensive care unit: practice recommendations. Pediatr Nurs, 36(2), pp. 85-96.

16. Malkin, B., (2009): The importance of patients' oral health and nurses' role in assessing and maintaining it. Nurs Times, 105(17), pp. 19-23.

17. Munro, C., Grap, M., Jones, D., McClish, D., \& Sessler, C., (2009): Chlorhexidine, tooth brushing, and preventing ventilator-associated pneumonia in critically ill adults. American journal of critical care: an official publication, American Association of Critical-Care Nurses, 18(5), pp. 428-437.

18. Oshodi, T., \& Bench, S., (2013): Ventilatorassociated pneumonia, liver disease and oral Chlorhexidine, British Journal of Nursing, (23)13, pp. 751-759.

19. Pedreira, G., Kusahara, M., \& de Carvalho, B., (2009): Oral Care Interventions and Oropharyngeal Colonization in Children Receiving Mechanical Ventilation american, 1, pp.141-145.

20. Prendergast, V., Jakobsson, U., Renvert, S., \& Hallberg, I., (2012): Effects of a standard versus comprehensive oral care protocol among intubated neuroscience ICU patients: results of a randomized controlled trial. The Journal of neuroscience nursing: journal of the American Association of Neuroscience Nurses, 44(3), pp.134-146.

21. Prendergast, V., Kleiman, C., \& King, M., (2013): The Bedside Oral Exam and the Barrow Oral Care Protocol: translating evidence-based oral care into practice. Intensive \& critical care nursing: the official journal of the British Association of Critical Care Nurses, 29(5), pp.282-290.

22. Sallam, S., Arafa, M., Razek, A., Naga, M., \& Hamid, M., (2005): Device-related nosocomial infection in intensive care units of Alexandria University Students Hospital. Eastern Mediterranean health journal $=$ La revue de sante de la Mediterranee orientale, al-Majallah alsihhiyah li-sharq al-mutawassit, 11(1-2), pp. 5261. 